\title{
An Investigator Blinded, Clinical Trial Assessing the Efficacy of Superfine Merino Wool Base Layer Garments (SMWBG) in Children with Atopic Dermatitis (AD) Measuring SCORAD ${ }^{1}, \mathrm{EASI}^{2}, \mathrm{POEM}^{3}$ and $\mathrm{DSA}^{4}$ Scores
}

\author{
Spelman Lynda Jane ${ }^{1,2 *}$, Supranowicz Madeleine Jane ${ }^{1,2}$, Davidson Kurt Alan ${ }^{1,2}$, Johnston Jesse James ${ }^{2}$, Yau \\ Benny ${ }^{1,2}$ and Holland Teagan Lea ${ }^{1,2}$ \\ ${ }^{1}$ Veracity Clinical Research: Brisbane, Australia \\ ${ }^{2}$ Queensland Institute of Dermatology: Brisbane, Australia
}

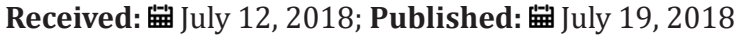

*Corresponding author: Spelman Lynda Jane, Veracity Clinical Research: Brisbane, Australia, Queensland Institute of Dermatology, Brisbane, Australia

\begin{abstract}
Atopic Dermatitis (AD) is a chronic inflammatory skin disease, which occurs most often in children compared with the adult AD population [5]. Wool is commonly considered an allergen and trigger for exacerbation of AD. However, Super Fine Merino Wool (SMW) has not been extensively studied and may show some effect in improving AD symptoms such as itch, erythema and induration. To explore this hypothesis, we performed an investigator blinded, repeated measures, self-controlled experimental design study with Super Fine Merino Base Layer Garments (SMWBG). SMWBG were worn by 29 patients with AD between the ages of 6 to 25 years over a 15 week period. We examined the tolerability and potential therapeutic effect of SMWBG (garments worn directly against the skin) in children and young adults with atopic dermatitis (AD). Response was assessed using validated scoring scales: Severity Scoring of Atopic Dermatitis $\left(\right.$ SCORAD $\left.^{1}\right)$, Eczema Area Severty Index $\left(\right.$ EASI $\left.^{2}\right)$, Patient-Orientated Eczema Measures $\left(\mathrm{POEM}^{3}\right)$ and a non-validated Dermatitis Severity Assessment (DSA ${ }^{4}$ ). Wilcoxon signed-rank tests were conducted to measure the difference between garment intervention phases. Statistically significant results were observed between the pre-garment intervention phase and the with-garment interventionphases for many of the scores. Results found that SMWBG were well-tolerated in children and young adults as an adjunctive therapy for the treatment of AD. This study was conducted in Brisbane, Australia between July 2014 and October 2015 and is Human Research Ethics Committee (HREC) approved.
\end{abstract}

Keywords: Atopic Dermatitis; Clinical Trial; Adjunctive Therapy; Superfine Merino Wool Base Layer Garments

Abbreviations: AD: Atopic Dermatitis; SMW: Super Fine Merino Wool; SMWBG: Super Fine Merino wool Base Layer Garments; SCORAD: Severity Scoring of Atopic Dermatitis; EASI: Eczema Area Severty Index; DSA: Dermatitis Severity Assessment; HREC: Human Research Ethics Committee; TCS: Topical Cortico Steroids; IP: Intervention Phase; TEWL: Transepidermal Water Loss

\section{Introduction}

Atopic Dermatitis (AD), otherwise known as eczema is a chronic inflammatory skin disease. AD occurs most often in children and the treatment options available are more complex when compared with the adult AD population [1]. The three prescribed main treatments in AD are: emollients, topical corticosteroids (TCS) and systemic therapies. TCS and diligent emollient application remain the mainstay of $\mathrm{AD}$ therapy. Systemic therapy and longterm TCS use have potential problems including skin atrophy and immuno suppression. There is a need for safer and better-tolerated alternatives in the management of $\mathrm{AD}$ [6]. There has been a wellestablished assumption that cotton, poly-cotton and silk are the preferred garment fabric choices for people with sensitive skin
$[7,8]$. Superfine Merino Wool (SMW) has been demonstrated to have little or no skin irritancy and has superior thermal and moisture buffering properties than other fabric options and therefore, may be suitable in patients with $\mathrm{AD}[9,10]$. Previous associations with wool and the prickle sensation have been further clarified as being related to a neurological response to fiber diameter irrespective of the fiber type [11,12]. The tolerability of SMWBG in adults with AD has been addressed in a previous study by [4] in 29 adult participants [4]. This study seeks to test the following Hypotheses:

a) Hypothesis 1: The fabric characteristics of SMWBG will be well tolerated as an adjunct therapy in participants with AD. 
b) Hypothesis 2: When SMWBG are worn by children and young adults, they will experience a reduction in their $\mathrm{AD}$ symptoms and signs.

\section{Method}

\section{Outcome Measures}

Primary outcome measures included assessing the tolerability of SMWBG measured using AD severity scores. Secondary outcome measures included assessing AD symptoms of sleep and itch through the validated measures: Patient Oriented Eczema Measurement $\left(\mathrm{POEM}^{3}\right)$ and Severity Scoring of Atopic Dermatitis (SCORAD $\left.{ }^{1}\right)$. The study design incorporated use of SCORAD ${ }^{1}$ and EASI $^{2}$ as the validated and standardized tools to evaluate the subjects' atopic dermatitis throughout the trial. POEM ${ }^{3}$ and participants' demographics were also recorded in this study. The study included a composite score of $\mathrm{AD}$ intensity, labeled by the investigators as the Dermatitis Severity Assessment (DSA ${ }^{4}$ ) score, a novel scale for rating the severity of dermatitis. This tool utilized a simple scoring system of 0 (none) to 3 (severe) each of redness, dryness, pruritus, swelling and pain with a total score range between 0 and 15 .

\section{Participants}

Participants were enrolled from a cohort of clinic patients identified with $\mathrm{AD}$ in Brisbane, Australia. Participants were referred from local community doctors and other dermatologists. A convenience sample of thirty-one (31) participants diagnosed with $\mathrm{AD}$ in accordance with the criteria of Hanifin \& Rajka [13], aged 6 to 25 years ( $M=11.86$ years of age) were enrolled in this study.

Table 1: Garment Group Descriptions.

\begin{tabular}{|c|c|c|c|c|c|c|}
\hline Garment Area & $\begin{array}{l}\text { Garment } \\
\text { Present }\end{array}$ & $\begin{array}{l}\text { Garment Not } \\
\text { Present }\end{array}$ & $\begin{array}{l}\text { Type of } \\
\text { Garments }\end{array}$ & $\begin{array}{c}\text { Participant } \\
\text { Garment Types }\end{array}$ & Available Sizes & Specifications \\
\hline Head & 0 & 29 & Beanie & Men & S-2XL & $\begin{array}{l}100 \% \text { merino wool, } 158 \mathrm{gsm}, \\
17.4 \text { micron }\end{array}$ \\
\hline \multirow[t]{6}{*}{$\begin{array}{l}\text { Upper Limbs Trunk } \\
\text { and Trunk }\end{array}$} & 15 & 14 & $\begin{array}{l}\text { Long Sleeve } \\
\text { Shirt }\end{array}$ & Women & 18-Aug & $\begin{array}{c}100 \% \text { merino wool, } 158 \mathrm{gsm}, \\
17.4 \text { micron }\end{array}$ \\
\hline & & & & Children & $6,8,10,12$ & $\begin{array}{l}100 \% \text { merino wool, } 161 \mathrm{gsm}, \\
18.0 \text { micron }\end{array}$ \\
\hline & & & & Men & S-2XL & $\begin{array}{l}100 \% \text { merino wool, } 158 \mathrm{gsm}, \\
17.4 \text { micron }\end{array}$ \\
\hline & 7 & 21 & $\begin{array}{l}\text { Short Sleeved } \\
\text { Shirt }\end{array}$ & Women & 18-Aug & $\begin{array}{c}100 \% \text { merino wool, } 158 \mathrm{gsm}, \\
17.4 \text { micron }\end{array}$ \\
\hline & & & & Children & $6,8,10,12$ & $\begin{array}{l}100 \% \text { merino wool, } 150 \mathrm{gsm} \text {, } \\
18.5 \text { micron }\end{array}$ \\
\hline & & & & Men & $S-2 X L$ & $\begin{array}{l}100 \% \text { merino wool, } 158 \mathrm{gsm} \text {, } \\
17.4 \text { micron }\end{array}$ \\
\hline \multirow[t]{4}{*}{ Trunk Only } & 2 & 26 & Singlet & Women & 18-Aug & $\begin{array}{l}100 \% \text { merino wool, } 158 \mathrm{gsm}, \\
17.4 \text { micron }\end{array}$ \\
\hline & & & & Children & $6,8,10,12$ & $\begin{array}{c}100 \% \text { merino wool, } 180 \mathrm{gsm}, \\
18.5 \text { micron }\end{array}$ \\
\hline & & & & Men & S-2XL & $\begin{array}{l}100 \% \text { merino wool, } 158 \mathrm{gsm} \text {, } \\
17.4 \text { micron }\end{array}$ \\
\hline & 4 & 24 & Underwear & Women & 18-Aug & $\begin{array}{l}100 \% \text { merino wool, } 158 \mathrm{gsm}, \\
17.4 \text { micron }\end{array}$ \\
\hline
\end{tabular}

Demographics were summarized by age, gender, race, ethnicity, height and weight. Thirty-one (31) participants were recruited into the study, two (2) participants chose to withdraw for personal reasons and did not complete the study and were excluded from stastistical analysis. No participants had worn SMWBG prior to commencing the study.

\section{Study Design}

The study was conducted in Brisbane, Australia. All participants had AD as defined by Hanifin and Rajka. ${ }^{13}$ Participants were recruited between July 2014 (Winter) and January (Summer) 2016 with the last patient completing the study in April (2016). It is important to note that seasonal variations in temperature in Brisbane were minimal during this period of time [14]. This study employed a clinical trials design whereby a with-garment intervention phase (IP) (where participants wore SMWBG for 5 weeks), measuring $\mathrm{AD}$ parameters, was compared with pre-garment IP and postgarment IP where participant's normal clothing was worn. This study employed a repeated measures design where each patient's outcome measures were compared between pre- and post-garment, so that individual differences could be better accounted for in the error term. To minimise the effect of washing detergent bias throughout the study, all participants washed their garments with Martha Gardner Wool Mix ${ }^{\mathrm{TM}}$ laundry detergent. The participants were instructed to wear the garments for a minimum of 6 hours per day. This time interval was chosen to avoid interference with other clothing requirements for example: school uniforms. Base layer garments were chosen as they were in direct contact with the skin. 


\begin{tabular}{|c|c|c|c|c|c|c|}
\hline & & & & Children & 16-Jun & $\begin{array}{l}100 \% \text { merino wool, } 158 \mathrm{gsm}, \\
17.4 \text { micron }\end{array}$ \\
\hline & & & & Men & $S-2 X L$ & $\begin{array}{l}100 \% \text { merino wool, } 158 \mathrm{gsm}, \\
17.4 \text { micron }\end{array}$ \\
\hline \multirow[t]{3}{*}{ Lower Limbs } & 20 & 9 & Leggings & Women & 18-Aug & $\begin{array}{l}100 \% \text { merino wool, } 158 \mathrm{gsm}, \\
17.4 \text { micron }\end{array}$ \\
\hline & & & & Children & 16-Jun & $\begin{array}{l}100 \% \text { merino wool, } 158 \mathrm{gsm}, \\
17.4 \text { micron }\end{array}$ \\
\hline & & & & Men & $\begin{array}{l}4-7,7-10 \& \\
10-13\end{array}$ & $\begin{array}{c}60 \% \text { merino (19 micron), } 38 \% \text { nylon, } \\
2 \% \text { elastane. }\end{array}$ \\
\hline \multirow[t]{2}{*}{ Feet and Ankles } & 3 & 25 & Socks & Women & $3-8 \& 9-12$ & $\begin{array}{c}60 \% \text { merino (19micron), } 38 \% \text { nylon, } \\
2 \% \text { elastane. }\end{array}$ \\
\hline & & & & Children & $5-8 \& 9-12$ & $\begin{array}{c}62 \% \text { merino (19 micron), } 27 \% \\
\text { nylon, } 8 \% \text { coolmax, } 2 \% \text { elastane, } 1 \% \\
\text { polyester }\end{array}$ \\
\hline
\end{tabular}

Note: gsm is a measure of fabric weight and is reported in grams per square meter

\section{The Intervention}

Commercially sourced SMWBG were chosen as the intervention for this study. SMW is defined as wool fabric with a mean fiber diameter less than or equal to 18.5 micrometers. Garments included singlets, long and short-sleeved shirts, underwear, leggings and socks. All garments comprised $100 \%$ SMW with the exception of socks, which contain 60\% 19.0 micrometer merino wool and synthetic fibers. Participants were dispensed with a maximum of four different garment groups, based on the cutaneous distribution of their AD. Garment details are included in Table 1.

\section{Investigator Blinding Procedures}

The blinded team included assessors, principal investigator and sub-investigators. The investigators were not aware of the style or number of garments dispensed to each participant. At Visit 3 the unblinded team member randomly allocated garment types to participants [15]. The purpose of the randomisation procedure was to reduce scoring bias by the investigators. The unblinded team distributed and collected the garments from participants. Participants, care providers and non-assessors were unblinded. Participants were asked not to disclose the garment locations to the blinded team. Garments were given to participants in opaque bags and they did not wear the study garments to their visits. The blind was maintained throughout the study. Participants were allocated garment inclusion and exclusion areas as their own control. Participants wore the garments in areas identified by the unblinded team at Visit 3. 20 participants wore lower limb garments (pants or socks), 15 wore upper limb garments (short or long-sleeved shirt), 23 wore trunk garments (singlet or shirt).

\section{Visit Schedule}

(Figure 1) provides a visual representation of the timeline of participants visits:

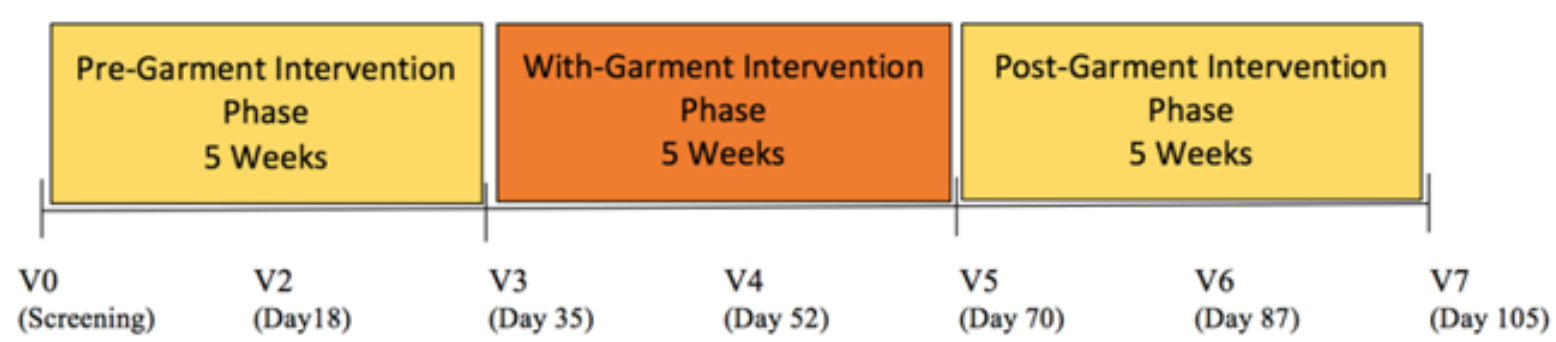

Figure 1: Timeline of Participant Visits and Intervention Periods

a) Pre-Garment Intervention Phase (IP): Initial screening (V0) and the first two visits (V2 and V3) represented participants' baseline scores before the garments were distributed and worn. At Visit 3, participants were given the garments to wear for the with-garment IP.

b) With-Garment IP: A 5-week IP comprised of two visits (V4 and V5) to measure AD severity whilst wearing the garments. At Visit 5, participants returned garments and scores were gathered. c) Post-Garment IP: A 5-week phase comprised of two visits (V6 and V7) to measure AD severity post garment.

\section{Measures of AD Severity}

Participant's demographics were obtained at Visit 0 (Screening). They included: age, gender, frequency of AD flares per week, clothing size and information about the fabric of garments and bedding that they usually used. In addition, the demographics contained information regarding creams, powders and medications 
used to treat their dermatitis and the estimated annual costs of these items.

At each visit, the following $\mathrm{AD}$ clinical assessments were performed

a) Overall severity via SCORAD ${ }^{1,} \mathrm{EASI}^{2}, \mathrm{POEM}^{3}$ and $\mathrm{DSA}^{4}$;

b) Severity of local target lesions in areas covered by merino wool garments, via SCORAD ${ }^{1}$, $\mathrm{EASI}^{2}$;

c) Severity of local target lesions not covered by SMWBG via SCORAD $^{1}$, EASI $^{2}$;

d) Tolerability to garments defined as no change or deterioration in the composite EASI ${ }^{2}$ and SCORAD ${ }^{1}$ assessments and/or recorded irritancy symptoms in the participants diary during the with-garment IP.

\section{Statistical Analysis and Ethical Considerations}

The Statistical Package for Social Science, version 24 (SPSS/ Mac: SPSSinc., Chicago, Ill, U.S.A) was used for the analysis. Wilcoxon signed rank test were used for comparison in the

Table 2: Descriptive Statistics.

\begin{tabular}{|c|c|c|c|c|c|}
\hline $\mathbf{N}$ & Min & Max & Mean & Std. Deviation & 11.86 \\
\hline Age & 29 & 6 & 25 & & 4.49 \\
\hline Female & 13 & & & & \\
\hline Male & 16 & & & 43.33 & 18.32 \\
\hline Weight (in kilograms) & 29 & 19.20 & 183.00 & 148.96 & 21.06 \\
\hline Height (in centimeters) & 29 & 112.50 & 27.80 & 19.08 & 3.63 \\
\hline BMI & 29 & 14 & & & \\
\hline
\end{tabular}

\section{POEM}

A Wilcoxon signed-rank test determined that there was a statistically significant decrease in the $\mathrm{POEM}^{3}$ total scores between the pre-garment intervention and the with-garment intervention phases $(M d n$ decrease $=1.67) \mathrm{z}=-2.79, \mathrm{p}=0.005, \mathrm{r}=0.518$. There was also a significant decrease in $\mathrm{POEM}^{3}$ scores between the pregarment intervention and the post-garment intervention phases (Mdn decrease=2.33), $\mathrm{z}=-3.385, \mathrm{p}<0.001, \mathrm{r}=0.63$.

\section{EASI}

The total EASI ${ }^{2}$ score was assessed using a Wilcoxon signedrank test. Note that Participant 31's post-garment intervention phase $\mathrm{EASI}^{2}$ scores were removed because it was identified as a significant outlier as determined by an assessment of box-plot. The tests that showed a statistically significant decrease between the pre-garment intervention and the with-garment intervention phases (Mdn decrease $=2.82$ ) $\mathrm{z}=-3.712, \mathrm{p}<0.001, \mathrm{r}=0.70$. Also, an overall statistically significant decrease in $\mathrm{EASI}^{2}$ scores between the pre-garment intervention and post-garment intervention phases (Mdn decrease=1.15 ) z=-2.14, $\mathrm{p}=0.032, \mathrm{r}=0.41$ was demonstrated. different intervention periods (IPs). The study was approved by an independent HREC (Bellberry Ltd. approval number: 2014-01045-A-13) approved $25^{\text {th }}$ June 2014. This trial was registred in ISRCTN (registration number: 53706986). All participants and or their legal guardians signed the appropriate participants consent form prior to commencing the trial. This trial was registered with ISRCTN retrospectively due to an oversight in the administration study processes. The authors confirm that all ongoing and related trials for this intervention were registered.

\section{Results}

The following section details the AD Severity Scores: SCORAD ${ }^{1}$, $\mathrm{EASI}^{2}, \mathrm{DSA}^{4}$ and $\mathrm{POEM}^{3}$ for this study. Unless otherwise stated, the comparison between the IP phases was conducted using a Wilcoxon signed rank test, to determine the statistical significance of the mean differences in scores.

\section{Descriptive Statistics}

Table 2 details the descriptive statistics for participants in this study. All other SCORAD ${ }^{1}$ total scores did not show a statistically significant increase or decrease of AD signs and symptoms.
DSA

Finally, a Wilcoxon signed-rank test determined that there was a similar statistically significant decrease in DSA ${ }^{4}$ scores between the pre-garment intervention and the with-garment intervention phases (Mdn decrease=1.33) $\mathrm{z}=-3.464, \mathrm{p}<0.001, \mathrm{r}=0.64$. There was also a significant decrease in $\mathrm{POEM}^{3}$ scores between the pregarment intervention and the post-garment intervention phases (Mdn decrease=1.17), $\mathrm{z}=-2.47, \mathrm{p}=0.014, \mathrm{r}=0.46$.

\section{Assessment of Safety and Tolerability}

Safety and tolerability of garments were measured through the AD severity scores. There were no significant increases in mean scores, physical signs or subjective symptoms between the pre-garment IP and with-garment IP or post-garment IP for all measures of AD Severity (redness, dryness, pruritus, swelling, pain, bleeding, weeping, cracking, flaking, roughness, papulation, oozing and crust, excoriation, lichenification, or sleep loss). Twenty (20) participants reported minor adverse events during the study period: twelve (12) reported self-limited viral upper respiratory tract infections, five (5) reported mild forms of impetigo with three 
(3) (Table 3), requiring oral antibiotics, and one (1) experienced urticaria whilst patting an animal. One (1) participant experienced a serious adverse event requiring hospitalization to treat a lower respiratory tract infection with antibiotics. None of these events

Table 3: SCORAD total Results Table.

\begin{tabular}{|c|c|c|c|c|c|c|}
\hline Score & Mdn Decrease & N & ties & z & P & \\
\hline $\begin{array}{c}\text { Pre-garment intervention and With-garment } \\
\text { intervention }\end{array}$ & & & & & \\
\hline Total Score & 7.63 & 28 & 0 & -3.74 & $<0.001^{* * *}$ & 0.71 \\
\hline Total Extent & 3.42 & 28 & 0 & -2.56 & $0.010^{* *}$ & 0.48 \\
\hline Total intensity & 1.33 & 28 & 0 & -3.26 & $<0.001^{* * *}$ & 0.61 \\
\hline $\begin{array}{c}\text { Pre-garment intervention and Post-garment } \\
\text { intervention }\end{array}$ & 2.33 & 29 & 0 & -4.14 & $<0.001^{* * *}$ & 0.77 \\
\hline Total Score & & & & \\
\hline Total Subjective Symptoms & 7.7 & 28 & 0 & -2.41 & $0.016^{* *}$ & 0.45 \\
\hline
\end{tabular}

Note: scores have been adjusted for ties.

\section{SCORAD}

A Wilcoxon signed-rank test determined that there was a statistically significant decrease in all SCORAD1 total scores between the following intervention phases as seen in table 3

\section{Discussion}

Overall, the intervention of SMWBG exhibited improvement in physical signs and subjective symptoms as demonstrated by improvement in $\mathrm{EASI}^{2}, \mathrm{SCORAD}^{1}, \mathrm{POEM}^{3}$ and $\mathrm{DSA}^{4}$ scores. Additionally, we identified positive aspects of wearing wool including; no garment-related reported adverse events, reusability of garments and practicality, and a sense of ownership of treatment for children and young adults being reported by patients.

\section{Physical Signs of Improvement}

The physical signs of improvement were evident in the decreased EASI ${ }^{2}$, SCORAD ${ }^{1}$ extent and POEM ${ }^{3}$ scores. This is in keeping with the findings of [16]. The intervention of SMWBG was shown to decrease $\mathrm{AD}$ symptoms during the with-garment intervention phase with regards to; erythema, oedema, papulation, excoriation, lichenification and dryness. Notably, the total SCORAD ${ }^{1}$ intensity and pruritus scores demonstrated a beneficial residual effect in the post-garment IP. The EASI ${ }^{2}$ scores, which reflected the individual rather than global inflammatory changes of the skin, indicated the symptoms of redness, thickness, scratching, lichenification and surface involvement were improved in the with-garment intervention phase. The $\mathrm{SCORAD}^{1}$ also indicated that there was global improvement in the physical signs. The secondary therapeutic effects on the non-treated areas of the head and neck were an unexpected outcome. This improvement may be explained by a decrease in the auto eczematization phenomenon i.e., by improving significant foci of skin inflammation, reactivity of the was considered by the principal investigator to be related to the garments. Throughout the entirety of the trial all participants tolerated the Martha Gardner Wool Mix ${ }^{\mathrm{TM}}$ laundry detergent. 
severity scores could potentially have been attributed to variations in frequency or potency of the topical steroid therapy. Three (3) participants also had short courses of oral antibiotic therapy for unrelated diseases during the trial which may have affected the course of their AD. This study was a single-arm trial and therefore has generalisability limitations. This study is part of a series of studies investigating the efficacy of SMWBLG in AD and future research is being performed to further explore this relationship.

\section{Future Studies}

From our initial investigations, it seems that there is an improvement in AD symptoms related to use of SMWBG. Further investigations into the complex relationship between SMW and $\mathrm{AD}$ severity remain to be performed. Future studies measuring transepidermal water loss (TEWL) in participants wearing SMW garments should be explored to assess the effect of hygral regulation and fatigue on AD. A proposed mechanism for wearing a superfine woolen keratin layer leading to a decrease in inflammatory signalling and degeneration of filaggrin (known to promote the construction of the cornified cell envelope) needs to be explored [18-19]. Double blinded designed studies would be appropriate to undertake. Studies comparing different fiber sources such as cotton, silk and polyester and other man-made fabrics measuring TEWL, AD severity scoring and thermal regulation in participants with $\mathrm{AD}$ may further clarify the therapeutic benefit and mechanism of action of SMWBG.

\section{Conclusion}

The intervention of SMWBG demonstrated improvement in the physical signs of $\mathrm{AD}$ in our cohort. This study supports the proposal that SMWBG provides a valuable adjunct therapy in the management of AD. There were no adverse garment-related effects, no reports of allergic or contact dermatitis with use and most importantly, no reports of worsening of AD symptoms. Patients reported the added benefits of comfort, practicality and reusability. Patients also reported a sense of ownership of treatment in children and young adults. Further investigation into the use of SMWBG is required to demonstrate the mechanisms behind the improvement of SMW in patients with AD.

\section{References}

1. Dermatology. (1993). Consensus Report: Severity scoring of atopic dermatitis: the SCORAD index. Dermatology 186(1): 23-31.

2. Hanifin J M, Thurston M, Omoto M, Cherill R, Tofte S J, et al. (2001) The eczema area and severity index (EASI): assessment of reliability in atopic dermatitis. Experimental dermatology 10(1): 11-18.

3. Charman C R, Venn A J, Williams H C (2004) The patient-oriented eczema measure: development and initial validation of a new tool for measuring atopic eczema severity from the patients' perspective. Archives of Dermatology 140(12): 1513-1519.

4. Spelman L, Johnston J, Holland T, Davidson K, Swan P, et al. (2015) A pilot study to determine the safety, tolerability and efficacy of merino base layers in the treatment of mild, moderate or severe dermatitis in a garment occluded area: AWI001. 2015. Poster presented at World Congress of Dermatology. Vancouver: Canada, USA.

5. Akdis C A, Akdis M, Bieber T, Bindslev-Jensen C, Boguniewicz M, et al. (2006) Diagnosis and treatment of atopic dermatitis in children and adults: European Academy of Allergology and Clinical Immunology/ American Academy of Allergy, Asthma and Immunology/PRACTALL Consensus Report. Allergy 11(8): 152-169.

6. Poetker DM, Reh DD (2010) A comprehensive review of the adverse effects of systemic corticosteroids. Otolaryngologic Clinics of North America 43(4): 753-768.

7. Ricci G, Patrizi A, Bendandi B, Menna G, Varotti E, et al. (2004) Clinical effectiveness of a silk fabric in the treatment of atopic dermatitis. British Journal of Dermatology 150(1): 127-131.

8. Mason R (2008) Fabrics for atopic dermatitis. J Fam Health care 18(2): 63-65.

9. Li Y, Holcombe BV, De Dear R (1996) Enhancement of coolness to the touch by hygroscopic fibers: part II: physical mechanisms. Textile research journal 66(9): 587-594.

10. Li Y, Holcombe BV, Apcar F (1992) Moisture buffering behaviour of hygroscopic fabric during wear. Textile research journal 62(11): 619627.

11. Garnsworthy RK, Gully RL, Kenins P, Mayfield RJ, Westerman RA (1998) Identification of the physical stimulus and the neural basis of fabricevoked prickle. Journal of Neurophysiology 59(4): 1083-1097.

12. Naylor GR (1992) The role of coarse fibres in fabric prickle using blended acrylic fibres of different diameters. Wool Technology and Sheep Breeding 40(1).

13. Hanifin JM, Rajka G (1980) Diagnostic features of atopic dermatitis. Acta Derm Venerol 60(92): 41-47.

14. Patrizi A, Savoia F, Giacomini F, Tabanelli M, Gurioli C (2009) The effect of summer holidays and sun exposure on atopic dermatitis. Giornale italiano di dermatologia e venereologia: organo ufficiale, Societa italiana di dermatologia e sifilografia 144(4): 463-466.

15. Urbaniak GC, Plous S (2017) Research Randomizer [Computer software]. Retrieved on June 22, 2013.

16. Su JC, Dailey R, Zallmann M, Leins E, Taresch L, et al. (2017) Determining Effects of Superfine Sheep wool in Infantile Eczema (DESSINE): a randomized paediatric crossover study. Br J Dermatol 177(1): 125-133.

17. Cunningham MJ, Zone JJ, Petersen MJ, Green JA (1986) Circulating activated (HLA-DR-positive) $\mathrm{T}$ lymphocytes in a patient with autoeczematization. J Am Acad Dermatol 14(6): 1039-1041.

18. Smith FJ, Irvine AD, Terron-Kwiatkowski A, Sandilands A, Campbell LE, et al. (2006) Loss-of-function mutations in the gene encoding filaggrin cause ichthyosis vulgaris. Nature genetics 38(3): 337-342.

19. Elias PM, Hatano Y, Williams ML (2008) Basis for the barrier abnormality in atopic dermatitis: outside-inside-outside pathogenic mechanisms. Journal of Allergy and Clinical Immunology 121(6): 1337-1343. 
ISSN: 2574-1241

DOI: $10.26717 / B J S T R .2018 .07 .001450$

Spelman Lynda Jane. Biomed J Sci \& Tech Res

(C) (i) This work is licensed under Creative

Submission Link: https://biomedres.us/submit-manuscript.php

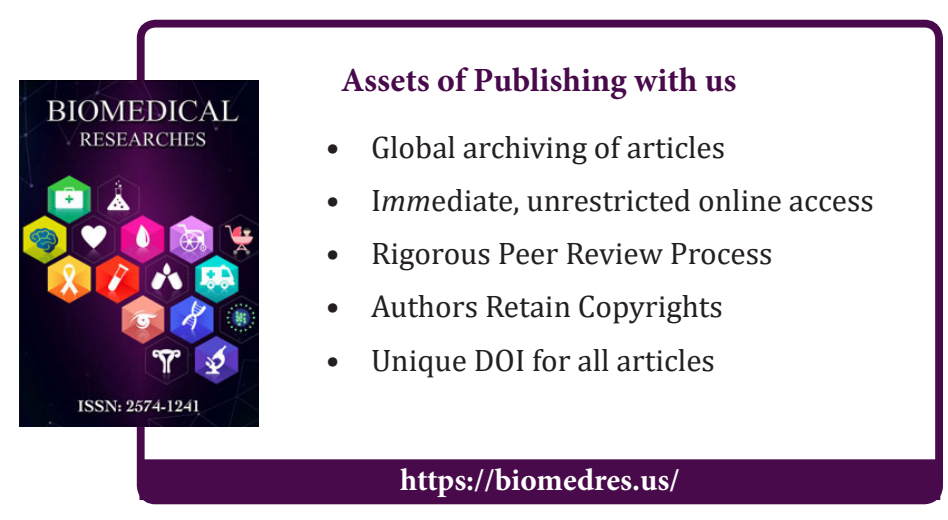

